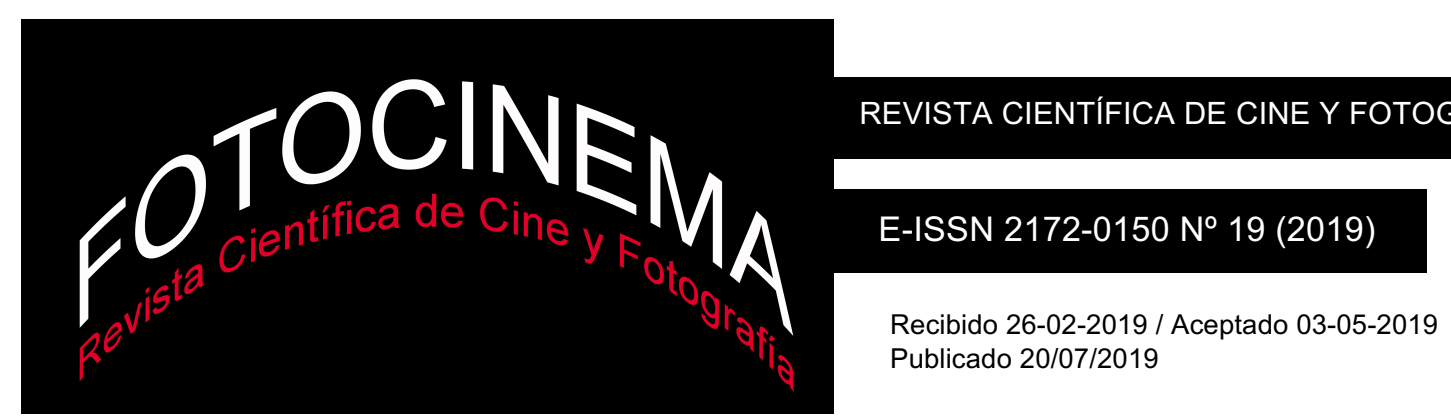

\title{
Calígula (1979), ¿cine erótico o cine pornográfico?
}

\section{Caligula (1979), erotic cinema or pornographic cinema?}

\section{Resumen}

Carlos García Carballo

Universidad de Córdoba, España carlosgarciacarballo@gmail.com

La evolución del cine ha ido desencadenando diferentes tipos de géneros cinematográficos, y es que entre todos los géneros existentes, hay un género que ha sido un poco apartado de las principales líneas de investigaciones en cinematografía, y que por ende, no tiene un gran volumen de literatura que pueda suponer una buena base científica para seguir creciendo académicamente hablando. La controversia entre el cine erótico y el pornográfico ha estado presente a lo largo de la historia del cine, siendo ambos géneros mal vistos. Para ello hemos desarrollado un proceso interpretativo acompañado de una ficha para analizar las escenas seleccionadas. Tinto Brass hace un uso exquisito del voyerismo en el espectador mostrando el sexo como una forma artística para mostrar la realidad en la gran pantalla su obra Calígula. Por consiguiente, en el espectador consigue reflexionar y meditar sobre la gran diferencia entre el disfrute contemplativo de un desnudo o de una relación sexual con amplios significados dramáticos, estéticos y humanos. Con todo esto, finalmente Calígula se puede catalogar dentro del cine softcore.

\begin{abstract}
The evolution of cinema has been triggering different types of film genres, and is that among all existing genres, there is a genre that has been a bit removed from the main lines of research in film, and therefore, does not have a large volume of literature that can suppose a good scientific base to continue growing academically speaking. The controversy between erotic and pornographic cinema has been present throughout the history of cinema, both genres being badly seen. For this we have developed an interpretive process accompanied by a file to analyze the selected scenes. Tinto Brass makes an exquisite use of voyeurism in the spectator, showing sex as an artistic way to show the reality on the big screen of his work Caligula. Therefore in the viewer gets reflected and meditate on the great difference between the contemplative enjoyment of a nude or a sexual relationship with broad dramatic, aesthetic and human meanings. With all this, finally Caligula can be classified as softcore cinema.
\end{abstract}

Palabras clave: cine erótico; Caligula; interpretación fílmica; Tinto Brass.

Keywords: Erotic Cinema; Caligula; Film Interpretation; Tinto Brass. 


\section{Introducción}

La evolución del cine ha ido desencadenando diferentes tipos de géneros cinematográficos. Algunos, como el Western, han sido clásicos que han proporcionado a la historia del cine películas como Horizontes lejanos (Bend of the River - Anthony Mann, 1952) o Las uvas de la ira (The Grapes of Wrath-John Ford, 1940), el cine de terror con clásicos como $E l$ exorcista (The Exorcist -William Friedkin, 1973) o Poltergeist (Tobe Hooper, 1982). Estos dos géneros, como ejemplo de otros muchos, han ido dejando a lo largo de la historia, películas que han supuesto joyas cinematográficas merecedoras de numerosos estudios.

Dicho lo anterior hemos visto como desde los orígenes del cine, podemos encontrar escenas de contenido sexual que han seguido la tradición de la fotografía licenciosa (Gubern, 2005, p. 9). Con esto queremos decir que erotismo y sexualidad "han estado presentes en el cine desde sus inicios, ya sea porque es una realidad inseparable de la condición humana o porque el deseo y el placer son vías naturales para la creación artística" (Aranda López, 2015).

Entre todos los géneros existentes, hay uno que ha sido un poco apartado de las principales líneas de investigación en cinematografía y que por ende no tiene un gran volumen de literatura que pueda suponer una buena base científica para seguir creciendo de forma académica y científica. Pese a ello, algunos autores españoles como Carmona (2010) y Calleja (2013) han dedicado parte de sus investigaciones a este género un poco apartado. González Caldito (2015) recoge que la palabra sexo es la que más se busca en todos los motores de Internet, por lo que, aunque no sea de un interés para la ciencia cinematográfica en general, este término para la sociedad despierta no mucho menos que algo de curiosidad.

En lo relativo al concepto erótico y erotismo, es importante tener presente que tanto su descripción literaria como artística han ido cambiando a lo largo de las distintas etapas históricas y sociales -no únicamente en su grado de 
explicitud, sino por su adaptación a los códigos morales, políticos o sociales-imperantes en cada período (Arroyo Martínez, 2010, p. 143).

\section{Cine erótico vs cine pornográfico}

A lo largo de la historia, el cine erótico ha sufrido el estigma de lo pornográfico, puesto que la sociedad casi siempre ha tildado el cine erótico de pornográfico, lo que ha supuesto una marca negativa o una mancha que ha motivado la repulsa social hacia este género en cuestión. Como Malpartida Tirado (2012, p. 176) apunta:

El modo de determinar la frontera entre lo erótico y lo pornográfico es muy diferente en literatura y cine. [...] de mostrarse explícitamente su contenido en una película, debería devenir en cine porno casi siempre, de modo que u operan autocensuras continuas, o al filme no se le permitiría el ingreso en el circuito de exhibición estándar.

Sobre esta delimitación entre lo erótico y la pornografía en el cine y la literatura se aprecia claramente en las obras del escritor estadounidense James M. Cain Double Indemnity (1944) y The Postman Always Rings Twice (1946). Ambas obras literarias tienen una carga sexual que a la hora de llevar al cine tanto Perdición (Double Indemnity - Billy Wilder, 1944) como El cartero siempre llama dos veces (The Postman Always Rings Twice - Tay Garnett, 1946) ambos cineastas tuvieron que usar "limitaciones infantilizantes ${ }^{1 “}$ de las escenas para poder conseguir transmitir al público la esencia de los libros que siempre fueron ineluctables sobre el sexo (Forshaw, 2015, p. 27).

Arroyo Martínez (2010, p. 145) recoge una definición de erotismo muy abierta que puede abarcar desde la alusión indirecta y presentación del tema en forma de deseo, llegando incluso a la inclusión de escenas sexuales encadenadas y variadas que consiguen devorar tanto el argumento como el guion de la película, puesto que éstos pasan a un segundo plano de interés. Ahora bien, en otras ocasiones, en películas como Flesh (Paul Morrissey,

1 "Working within the infantilising constraints of the time to convey". 
1968), consiste en una serie de escenas poco estructuradas donde cualquier intento de una narrativa más concentrada fue conscientemente excluido (Forshaw, 2015, p. 156).

Por otro lado, González Requena (citado en Rojas Bez, 1997, p. 48) se atreve a postular una diferencia entre ambos bastante completa:

Es concebible postular una rotunda diferencia entre el erotismo y la pornografía. El erotismo está del lado del velo, del juego con una demora en la que un símbolo -estructurado en el juego de la presencia y de la ausencia- se invoca. [...] el erotismo participa de una relación sagrada con el sexo, la misma que hace posible el amor, es decir, el reconocimiento del otro como diferente, como no especular, como alguien que, por diferente, puede dar y recibir.

Del mismo modo, este autor continúa recogiendo una amplia y profunda definición de pornografía, que a diferencia del erotismo:

se reconoce en la irrupción de una mirada profanadora: inscrita toda ella en el ámbito de lo imaginario, en una pulsión de ver hasta el final, de devorar con la mirada, no acepta, pues, ningún límite, no reconoce ningún misterio, nada sagrado ante lo que la mirada deba cesar pues no acepta, después de todo, diferencia alguna con el objeto de su mirada. El otro, pues, no es reconocido como ser -diferente-, sino tan solo como objeto de apropiación especular.

Dentro de esta vorágine conceptual que presenta el cine erótico y el cine pornográfico, hay que destacar un concepto que Arce recoge dentro de su estudio. El término sexploitation movies que deriva del vocablo inglés y podemos definirlo como cine de explotación sexual o del sexo. En otras palabras, Arce (2014, p. 102) define este cine como el que utiliza el sexo como principal reclamo para su comercialización orientado al consumo, desvinculado del mainstrem y de las corrientes artísticas.

La pornografía tradicional se caracteriza por atribuir roles determinados a los sujetos que representa y, por tanto, trasladar unas relaciones de poder basadas en la supremacía de lo blanco, anglosajón, heterosexual y masculino, frente a cualquier otra identidad. [...] cosifica los cuerpos femeninos, patologiza determinadas corporeidades y constriñe las posibilidades de sentir deseo y las prácticas sexuales realizables. (Ares y Pedraz Poza, 2011, p. 98) 
A esto también hay que añadir, tal y como postula Forshaw (2015, p. 155) en su trabajo, que las películas pornográficas generalmente mantienen poco interés por las sutilezas que sí tiene el cine erótico, no reparando en su objetivo principal: proporcionar material para la excitación sexual y la liberación en audiencias más interesadas en ver la interacción lubricada de los genitales humanos, para que los espectadores tengan la seguridad de que esto es real y no una simulación de los actores. Esto que ilustra Forshaw se pierde en muchas ocasiones por parte de los directores de este tipo de cine, dado que en su intento por hacer una producción donde se busca a unos actores con unos genitales que sean del gusto de la audiencia, se pierde la calidad interpretativa de dichos actores $\mathrm{y}$, por ende, la credibilidad desaparece ante unos entes que mantienen relaciones sexuales sin ser capaces de traspasar esas sensaciones, emociones y sentimientos lascivos que es lo que la audiencia busca.

Rojas Bez (1997, p. 48) determina un error común en cuanto a la definición de la pornografía por parte de la literatura científica hasta el momento, resaltando que:

[...] llamar pornografía a toda incitación sexual, e incluso a toda sensualidad vinculada a la presentación de lo sexual por medio de imágenes o descripciones; sensualidad a la que generalmente se aplica no solo una simple catalogación de "pornografía" o "erotismo acentuado", entre otras, sino además su condena o su censura.

Todo esto nos abre la puerta a cuestionarnos la realidad sobre la propia pornografía y qué es lo que la diferencia del cine erótico. Para ello, retomando a Roja Bez, se puede determinar que la pornografía es:

1. Un fenómeno que tiene que ver, al menos, con dos elementos o polos y con un proceso (sicológico, expectativo...) de recepción: un sujeto (o sujetos) que asume de manera particular determinado objeto (escena, obra...).

2. Un fenómeno que conlleva, más que la gratuidad de lo sexual, su carácter de medio, recurso para provocar excitaciones y satisfacciones no propiamente estéticas, y ni siquiera vagamente sensuales, sino 
sexuales, sustitutivas de la sexualidad "normal" y, con frecuencia, compensatorias de emociones asociadas a determinadas estructuras de personalidad (sadomasoquismo, etc.).

3. Una frecuente manipulación, de un público susceptible de ello, para "impactar", "impresionar", por medio de la presentación de "lo sexual" no común o exacerbado en mayor o menor grado, y la pérdida de la intimidad y de todo distanciamiento respetuoso o considerado del "otro".

Con esto, este autor nos proporciona una visión bastante exhaustiva sobre la percepción de la pornografía que permite que nos hagamos una clara idea sobre ella y, por consiguiente, diferenciarla del cine erótico. Dicho lo anterior, la delimitación entre erótico y pornográfico no es tan fácil como se podría haber llegado a pensar en un primer momento, ya que como se ha visto existen matices que no se deben obviar según los autores, y también según la película a la que nos refiramos en una época concreta. Todo esto contribuye a que el filme pueda moverse en la delgada línea que separa ambos géneros de cine que no son fáciles de delimitar de forma global o genérica.

Como comenta González Caldito (2015), la pornografía no es un género autónomo por sí solo, sino que deriva del erótico. Del mismo modo afirma que "no sólo nace con la intención de desvelar los deseos e intenciones más ocultas del ser humano, sino también como herramienta de denuncia y destructor de una tradición asfixiante que incluso condenaba a muerte por su uso".

En un intento de analizar ambos géneros, podemos decir que a diferencia del cine erótico, en el cine pornográfico "su capacidad narrativa, sea la que fuere, apenas se tiene en cuenta a la hora de analizar la obra desde una perspectiva narratológica” (Mendíbil Blanco, García García y García Guardia, 2017, p. 155). Con esto es debido a que como Raven Touchstone revela en una entrevista, los guionistas del cine pornográfico siempre tienen que construir una historia en base a las escenas de sexo que el director o directora desea 
filmar (Rouner, 2014), por lo que podemos apreciar que la historia es solo una herramienta narratológica que le da sentido al nexo entre una escena de sexo y la siguiente. En contraste con esto, los creadores de películas eróticas (a diferencia de las pornográficas) se enorgullecen habitualmente de las cualidades sensoriales, visualmente agradables para las mujeres de su material y los valores de producción bien tapizados (Forshaw, 2015, p. 154155).

En lo relativo a la representación sexual de las escenas, Forshaw (2015, p. 125) postula que cualquier representación de dicho acto en una película erótica -a menos que esté diseñada para una simple excitación como pasa con la pornografía en general- debe incorporar una variedad de elementos: 1) un primer plano del personaje para que los protagonistas que estamos viendo permanezcan claramente diferenciados (a diferencia del "trozo de carne anónimo de la pornografía"2); 2) el avance del flujo narrativo, suponiendo que la escena sexual no se incorpora solo con el propósito de excitar; y 3) una mise en scène que refleja el estilo cinematográfico general de la película. En otras palabras, para tener éxito, tales escenas siempre deben ser asimiladas orgánicamente en la película en lugar de insertarse arbitrariamente.

Rodríguez Centeno y Corredor (1997, p. 40) definen el cine erótico como un fenómeno sociológico y, por ende, la publicidad de este tipo de cine que ofrece al espectador un mundo de sensaciones ocultas durante cuatro décadas. Todo esto nos hace ver este género como una oferta de sensualidad que cautiva la atención de los espectadores en busca de unas sensaciones que hasta el momento estaban ocultas al ojo del espectador.

La narrativa del cine pornográfico ha sido objeto de muchas polémicas y en algunos casos de estudio, pero asumiendo generalmente que el argumento o trama del film era el contenedor de todo el relato, subestimando la narratividad de la esencia propia del porno: las escenas de sexo explícito. (Mendíbil Blanco et al, 2017, p. 155).

2 Término traducido de "anonymous flesh of pornography". 
Sintetizando, pues, diremos que en el cine erótico el desnudo y el sexo debe estar justificado, no puede ser algo superfluo y casual, con esto queremos decir que esas escenas deben aportar un valor a la narración y a la historia, sin ser necesariamente el eje de la narración la sucesión de escenas sexuales a lo largo del filme.

La narración del cine pornográfico y del cine erótico es una de las claves que algunos autores tienen en consideración a la hora de matizar cada uno de los géneros y así distanciarlos entre ellos. Hemos ido viendo que en determinados grupos sociales y épocas, en muchas ocasiones el cine erótico ha sido tachado de pornográfico, pero el estudio de Mendíbil Blanco et al (2017) resulta clave dentro de la distinción de ambos géneros. En su investigación, estos autores estudian el núcleo del relato del cine pornográfico, para llegar a afirmar que las escenas de sexo son la esencia del relato, llegando a compararlas con las escenas de baile en los musicales.

En otras ocasiones, como sucede en Gilda (Charles Vidor, 1946), la joven Rita Hayworth deja impreso en la retina del espectador una escena que ha pasado a la posteridad por su sensualidad y su erotismo más que justificado en la narración del filme: el striptease. En esta escena, la actriz lleva un traje de seda oscura con un sugerente escote, y acompañada de la canción "Put the Blame on Mame” empieza a desvestirse únicamente de uno de sus guantes, pero es tan grande la sensualidad con la que lo hace, que es capaz de transmitir con más fuerza que si la composición de la escena consistiese en un desnudo integral; dicho de otra manera, indiscutiblemente logra transmitir una sexualidad enérgica y abierta incluso dentro de los límites de lo que el censor permitiría en esta secuencia memorable (Forshaw, 2015, p. 31).

Hay que tener cuenta que la diferenciación de ambos géneros también radica en el grado de mostración y realización de la propia sexualidad, ya que de esta manera se trataría, en última instancia, de una distinción cuantitativa (número de desnudos, partes del cuerpo que se muestran y explicitud de actos sexuales) y no cualitativa (Malpartida Tirado, 2012, p. 179). Ahora bien, podemos decir que, aunque en muchas ocasiones se ha considerado que la 
diferencia está estudiada desde el aspecto cuantitativo frente al cualitativo, podemos discrepar pues, como ocurre con la película objeto de este estudio en su versión con las escenas extras filmadas a posteriori por el productor Bob Guccione, dada su forma de tratar el sexo-; esta versión fue la que probablemente hizo que se clasificara y se censurará como pornográfica. Es por esto que como argumentan Mendíbil Blanco et al (2017, p. 160), "si en el porno separamos un estrato de la historia o lo narrado, y un estrato del discurso o lo narrante, lo narrado adquiere un plano subordinado", en otras palabras, el cine pornográfico pierde lo que es sin las escenas de sexo, ya que lo narrado es simplemente un simple nexo entre las diferentes escenas sin aportar nada a los hechos que discurren en el filme.

En determinadas ocasiones esto se puede dar debido a la teoría de que el cine pornográfico "prioriza la forma sobre el contenido" (Mendíbil Blanco et al, 2017, p. 155).

\section{El género erótico como cultura del cine}

García Gómez (2017, p. 7) dice que "el erotismo implica un elemento de refinamiento, de sofisticación: es sobre todo una creación cultural, y de ahí las diferencias en el modo de entenderlo entre diferentes civilizaciones y épocas". No podemos olvidar que en la relación del sexo y el erotismo podemos considerar que constituye una fuente de placer, en muchas ocasiones visto también como una relación con poderosas armas de dominación. Dando lugar a un nexo entre sexo y poder, el cual está rodeado de erotismo, como podemos ver en la película Dishonored (Josef von Sternberg - 1931) donde la protagonista del filme (interpretada por una joven Marlene Dietrich) es la viuda de un oficial que para sobrevivir tiene que dedicarse a la prostitución y es requerida para ser una agente especial por el servicio secreto austriaco convirtiéndose en una heroína pese a sufrir las burlas de un agente ruso llamado Kranav (Victor McLaglen).

Del mismo modo, pocos años después en la película Capricho Imperial (The Scarlet Empress - Josef von Sternberg, 1934) este director vuelve a recurrir 
de la actriz Marlene Dietrich para representar a una joven virginal princesa que se casa con el Gran Duque de Rusia (Sam Jaffe), el futuro zar Pedro I el Grande, y con el paso de la película vemos como su personaje cambia hasta convertirse en la poderosa figura que se viste como un soldado y ejerce poder en habitaciones repletas de hombres, sin temor a esclavizarlos sexualmente en la privacidad de su habitación (Forshaw, 2015, p. 20).

La década de los años 50 fueron años donde los bailes supusieron nuevas formas de esquivar las censuras de la "Legion of Decency", entre ellas podemos destacar la película Picnic (Joshua Logan, 1956) donde en ese baile la sensualidad y la parte erótica recae sobre la figura masculina protagonizada por William Holden. El director consigue fotografiar a su estrella masculina de una manera tan atractiva y sensual como su estrella femenina, y su baile durante el picnic en la comunidad de la aldea se realiza con el máximo atractivo erótico, y sin lugar a duda lo que estamos presenciando es más un ritual sexual que uno romántico (Forshaw, 2015, p. 38).

A principio de los sesenta se estrena La dolce vita (Federico Fellini - 1960), una película sensual y bastante sugerente en la escena donde acariciando sensualmente su propio cuerpo con un abrigo de piel, el director presenta un elemento táctil del cual el público está claramente destinado a ser consciente (esta es una de las razones por las cuales la secuencia aún funciona hoy, a pesar de su relativa modestia), e incluso esa escena del beso en la Fontana di Trevi (Roma, Italia) que se ha quedado impregnada en la retina de todo espectador por la sugerente sensualidad y el erotismo que proyectan los actores.

Ya en los años setenta cualquier escena sexual se podía mostrar sin temor a ninguna penalización de tipo legal, existían grupos sociales con ideales muy conservadores y bastantes religiosos que no están satisfechos con este panorama. Esta situación provocó en ese momento la autocensura de los propios creadores, que variaba en cuestión de grados de manera notable llegando a limitar en términos preocupantes su libertad creadora (Arroyo Martínez, 2010, p. 145). 
Habría que decir también que en el caso de El contrato del dibujante (The Draughtsman's Contract - Peter Greenaway, 1982) donde el director desarrolla un ensayo teórico de forma visual con su estilo formal y estético, y donde el tema del discurso teórico subyacente es la relación entre sexo, matrimonio, propiedad material, clase y linaje, entre otros. Nos encontramos ante una película ambientada en un período muy específico de la historia de Inglaterra (finales del siglo XVII) que retrata un mundo rígidamente hobbesiano en el que todas las relaciones humanas están basadas en el poder y toda la motivación humana es una expresión de un material particular, erótico o de interés social (Reidar, 2013).

Dentro de las películas del director Josef von Sternberg vemos un nexo entre sexo y poder que posteriormente podemos encontrar en el filme Salon Kitty (Salon Kitty - Tinto Brass, 1976), basada en hechos reales y donde cuenta cómo en un burdel las prostitutas polacas son sustituidas por bellas e inteligentes alemanas que deben simpatizar con el partido nazi; encontrándose una oposición a la imperiosa regla de que estas bellas jóvenes sean nuevas espías de confidencias de hombres de negocios, dignatarios extranjeros y de los propios oficiales alemanes por parte de la dueña de este burdel. Para la mayor parte de sus admiradores, la película destaca por el erotismo altamente estilizado, por su sensualidad, la desnudez que no cesa a lo largo del metraje y dado que la mayoría de las orgías contienen planos de las zonas íntimas femeninas y semi-erecciones que en su momento hubieran sido un escándalo si los 18 minutos eliminados de la versión de Guccione hubieran sido proyectados (Forshaw, 2015, p. 79).

El erotismo ha estado privado mucho tiempo de poder ser proyectado en la gran pantalla en todo su auge por culpa de la censura que sufrió tanto este género como otros por gobiernos y organismos religiosos que veían una depravación en determinadas escenas subidas de tono. Aunque podemos decir que directores como Hitchcock usaron de forma sutil el desnudo dentro de sus películas sin que saltaran las alarmas de los censores. Un ejemplo de esta estrategia de evasión (Schaefer, 1999, p. 296) como es el caso de Psicosis (Alfred Hitchcock, 1960), donde se da un desnudo en la famosa escena de 
este filme sin que pueda ser finalmente censurado. De esta forma, la "sutileza del erotismo y la insinuación tomaron un protagonismo total en este contexto" (Aranda López, 2015).

\section{Metodología}

Calígula iba a ser una película que tomaría el desafío contra la censura todavía existente en esos años mediante la presentación de escenas de sexo duro y una violencia mostrada en un contexto de película tradicional que para muchos resultaría chocante en su visionado.

La selección de esta película como objeto de estudio radica en la necesidad de conocer los motivos por los cuales puede ser considerada por parte de la audiencia como perteneciente al género pornográfico, y considerado que cuando los intereses de Guccione se volvieron cinematográficos, Franco Rossellini le ofreció el proyecto de Calígula. Guccione se propuso cumplir estos mismos criterios, como lo haría cualquier estudio de cine importante.

Rara vez hay tres ediciones diferentes de una misma película, cada una diseñada para diferentes audiencias y disponible para la comparación entre ellas. Un ejemplo de esto es la película que nos trae a esta investigación: Calígula (Caligula - Tinto Brass, 1979). De las tres versiones existentes nos encontramos una con 45 escenas y de 124 minutos de duración, otra de 39 escenas y 102 minutos de duración, y por último tenemos la versión de Bob Guccione con un total de 51 escenas y 156 minutos de duración.

Dentro de este análisis, vamos a seleccionar las escenas 5, 6, 20, 21, 22 y 43 por su contenido más sexual dentro del filme. Estas escenas son aquellas más representativas de las que fueron rodadas por Tinto Brass (Rodrigues, 2014, p. 151) y que son un claro ejemplo de lo que se quiere demostrar con esta investigación. Para poder llevar a cabo el análisis y poder compararlo, basándonos en Gómez Tarín (2006) hemos llevado a cabo el siguiente esquema: 


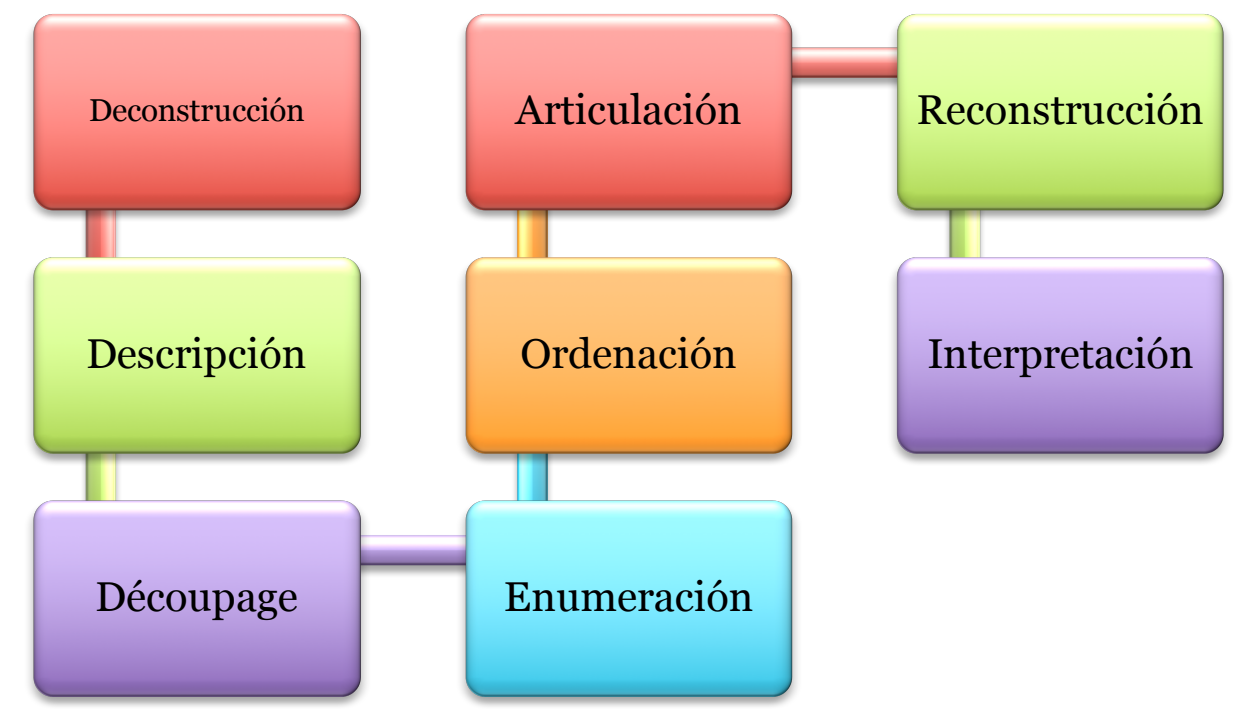

F1. Pasos para llegar a una buena interpretación filmica. Gómez Tarín (2006, p. 18).

\begin{tabular}{|c|l|l|}
\hline \multirow{2}{*}{ Fase descriptiva } & $\begin{array}{l}\text { Signos y códigos en el filme } \\
\text { de carácter sexual }\end{array}$ & \\
\cline { 2 - 3 } & Niveles de representación \\
de carácter sexual & \\
\hline \multirow{2}{*}{ Fase descriptivo- } & $\begin{array}{l}\text { El espacio y el tiempo } \\
\text { interpretativa }\end{array}$ & \\
\hline Fase interpretativa de vista & $\begin{array}{l}\text { Formas y recorrido de la } \\
\text { mirada en los elementos } \\
\text { sexuales }\end{array}$ & \\
\hline la escena & \\
\hline
\end{tabular}

F2. Ficha de análisis. Elaboración propia basado en Casetti y Di Chio (1994) y Bordwell (1995)

Para poder llevar a cabo este esquema nos basaremos en el trabajo de Casetti y Di Chio (1994) y Bordwell (1995) hemos usado una ficha como la siguiente con cada una de las escenas seleccionada y con ayuda de ella haremos un análisis de los elementos más significativos que nos permita ver si el filme sería considerado cine erótico o cine pornográfico: 
Es importante matizar que esta ficha será la guía en la que se analizarán aquellos elementos de contenido sexual (ya sean eróticos o pornográficos) que nos ayude con el objeto de estudio en esta investigación (así Calígula pueda ser clasificada como erótico o como pornográfico).

\section{Exposición}

\section{Escena 5}

Dentro de la fase descriptiva de esta escena cabe destacar el alto grado de iconicidad que presenta Tinto Brass a los espectadores. En ella, observamos un ambiente poco iluminado y que con ayuda de los planos y la angulación el director consigue transmitir al espectador el ambiente en el cual Tiberio disfrutaba con sus pequeños peces en la piscina. Así mismo, vemos la construcción de la escena muy teatral, donde no se aprecia un atisbo de recrear un espacio real.

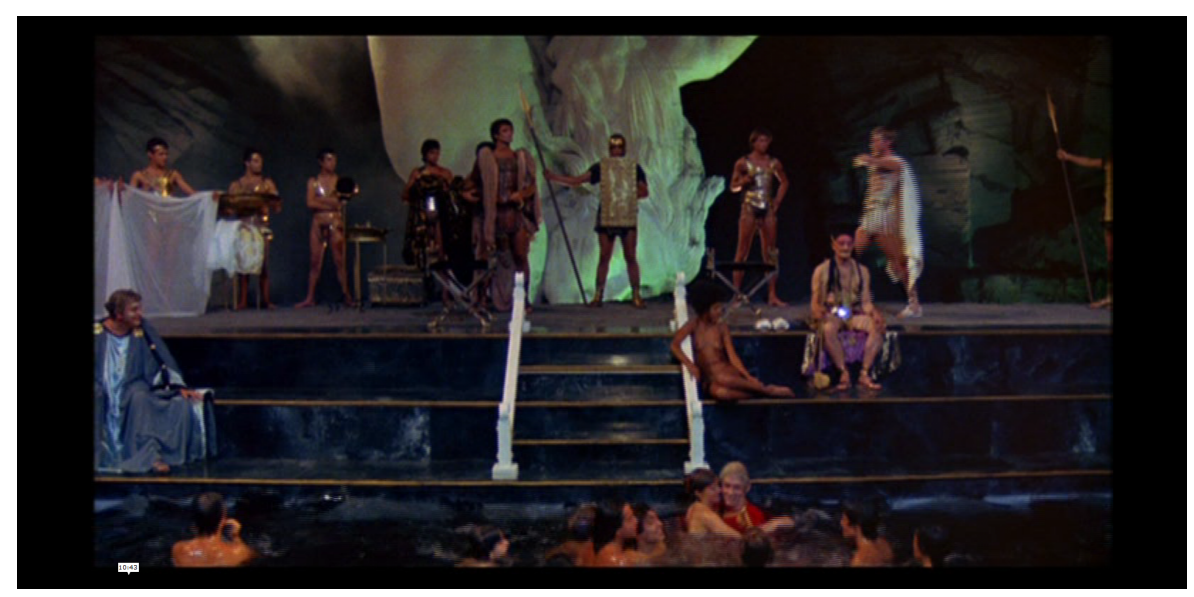

F2. Escena de Tiberio en la piscina. Calígula, Tinto Brass, 1979

Con ayuda del encuadre y de los tipos de planos en esta escena, el director incita al espectador a que haga un barrido con su mirada a todos los elementos presente en el encuadre (en este caso los cuerpos desnudos en la piscina y del séquito de Tiberio).

Tinto Brass quiere que el espectador sepa y empatice con el deseo de Calígula de ser el nuevo emperador, y es para ello que la presentación del personaje de Tiberio no es agradable ni físicamente ni en su forma de ser. 


\section{Escena 6}

Al igual que con el caso anterior, Tinto Brass lleva al máximo el grado de iconicidad en esta escena dado que es una de las más impactantes de la película por su grado de crueldad, violencia y contenido sexual explícito. Tinto Brass con ayuda de Danilo Donati nos evoca al trabajo de Fellini en Satiricón (Fellini - Satyricon, 1969). Para ello hacen uso de un fondo básico de niveles múltiples en una roca oscura donde predomina el color rojo en la iluminación frente a la túnica blanca que luce Tiberio en un ascenso en la escena que genera una energía que eleva el ritmo en la narración.

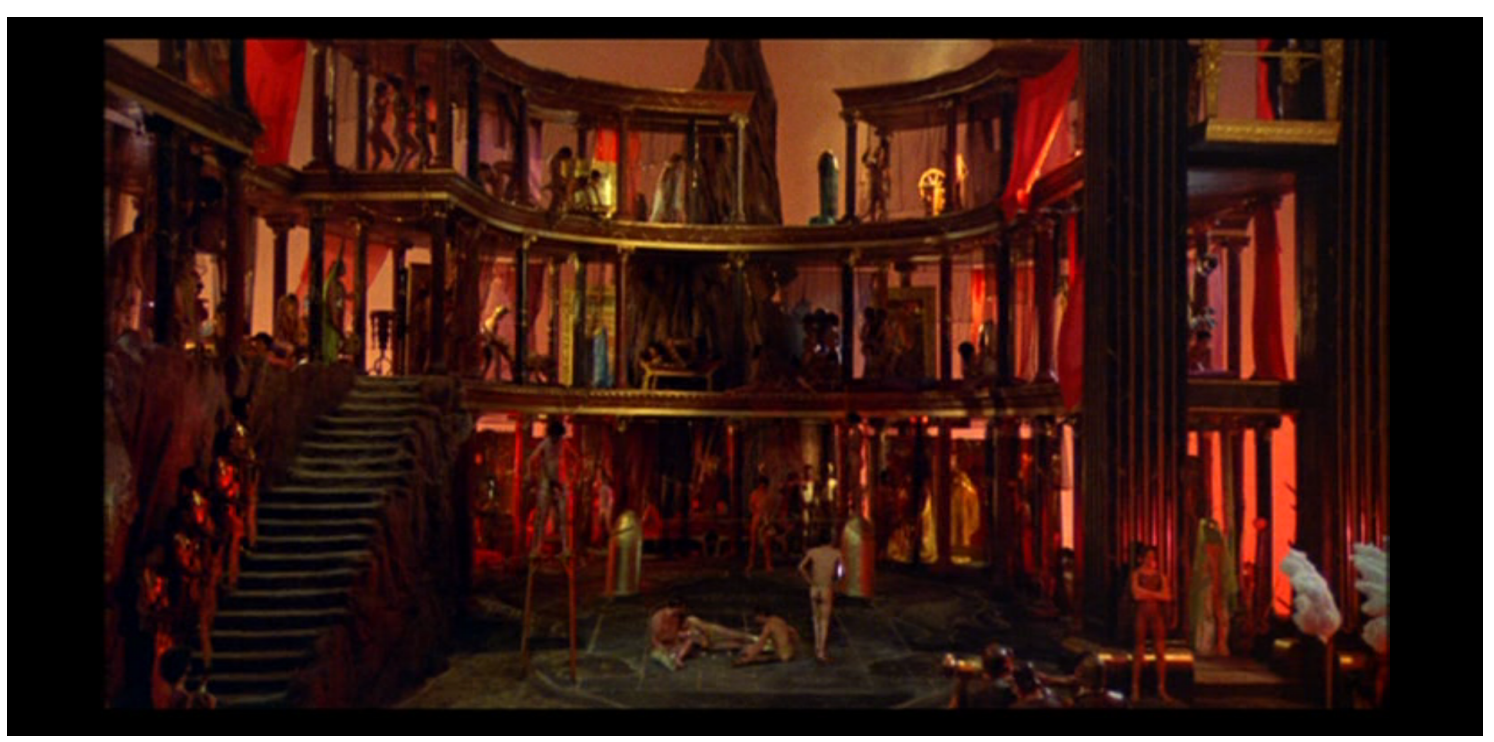

F3. Escena del interior de Villa Jovis. Calígula, Tinto Brass, 1979

Como observamos, esta escena está dividida en un fondo multinivel y de donde podemos apreciar que se recrea una demostración de actividades sexuales a cual más explícita: hombres en zancos con vistosas erecciones, mujeres con consoladores de oro entre sus senos, hombres masturbándose, maquinarias que simulan cunnilingus a una mujer, columpios sexuales e incluso penetraciones interraciales.

Entre todo este festín sexual, en su discurso Tiberio se distingue del resto de Roma por tener el poder, comparándose como un "pastor de cerdos”. Acto seguido vemos en escena a Tiberio Gemelo (primo de Calígula y del que se dice que acabará matando a Calígula) rehusando beber la copa de vino que le ofrecen inicialmente a Calígula y que este se lo da a su primo. Y es que antes 
que se lo vaya a beber, Tiberio se lo quita para que finalmente una esclava muera de forma inminente envenenada tras probar el vino.

Con esta escena se quiso poner de manifiesto la lucha por el poder de las clases en la época romana, ya que si Calígula hubiera bebido el vino, el siguiente emperador habría resultado ser Tiberio Gemelo. Del mismo modo, se refleja el miedo por la muerte de ser despojado del poder con el asesinato por parte de Tiberio que se había apartado de Roma, y a lo largo del filme apreciamos este mismo temor en el personaje de Calígula.

\section{Escena 20}

En esta escena Drusilla y Calígula hablan sobre el matrimonio, a lo que Calígula manifiesta su deseo de casarse con ella, pero debido a que son hermanos no podrían, por lo que ella le invita a buscar a una respetable mujer de la clase senatorial para poder tener un heredero. A raíz de esto Calígula vuelve a poner de manifiesto su temor a ser asesinado, en este caso con el que sería su propio hijo.

La escena termina con Drusilla manifestando su poder en Calígula solo con agarrarle los genitales, lo que nos da a entender como el sexo y el poder están muy ligados entre ellos hasta el punto que Drusilla con ayuda del sexo es también emperadora de Roma. Las imágenes en movimiento en esta escena combinan de forma alternativa diferentes códigos heterogéneos (Casetti - Di Chio: 1994,75$)$.

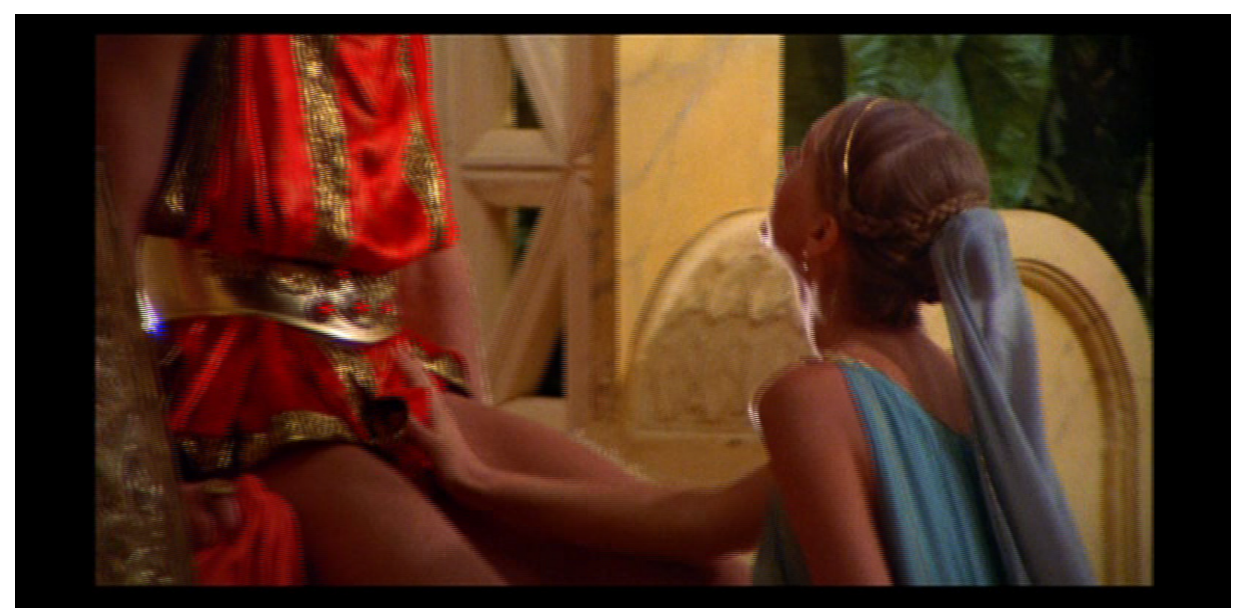

F4. Escena donde Drusilla usa el sexo como arma de convicción. Calígula, Tinto Brass, 1979 
En el plano que se aprecia en la Figura 4 refleja claramente como Tinto Brass quiso plasmar su concepto de la tiranía del poder que comenzó con Salon Kitty, vinculando el sexo con el poder de una manera muy particular. El sexo y el poder desde que ambos coexistieron dentro de una sociedad se han visto encauzados a compenetrarse y entenderse entre ellos. El poder al igual que el sexo, son dos aspectos que para muchos en la historia han supuesto un golpe de autoridad y de placer para aquel que lo ostentara.

\section{Escena 21}

Esta es una de las escenas más estéticas de la película, con un importante juego de colores y composiciones de planos. A diferencia con las escenas anteriores, el grado de iconicidad es relevante, aunque varía. En este caso, en la escena aboga por mostrar el placer sexual de las mujeres. El desarrollo de la escena muestra el punto de vista de que la mujer es conocedora de su placer y por ello se les muestra disfrutando entre ellas.

En la escena predomina el blanco (tanto en el decorado como en la vestimenta) y el agua, ambos símbolos de pureza y fertilidad en muchas religiones y a lo largo de la historia. A estas reuniones no está permitido el acceso de hombres, y es por ello que Calígula se disfraza de mujer para pasar desapercibido dentro de este acontecimiento.

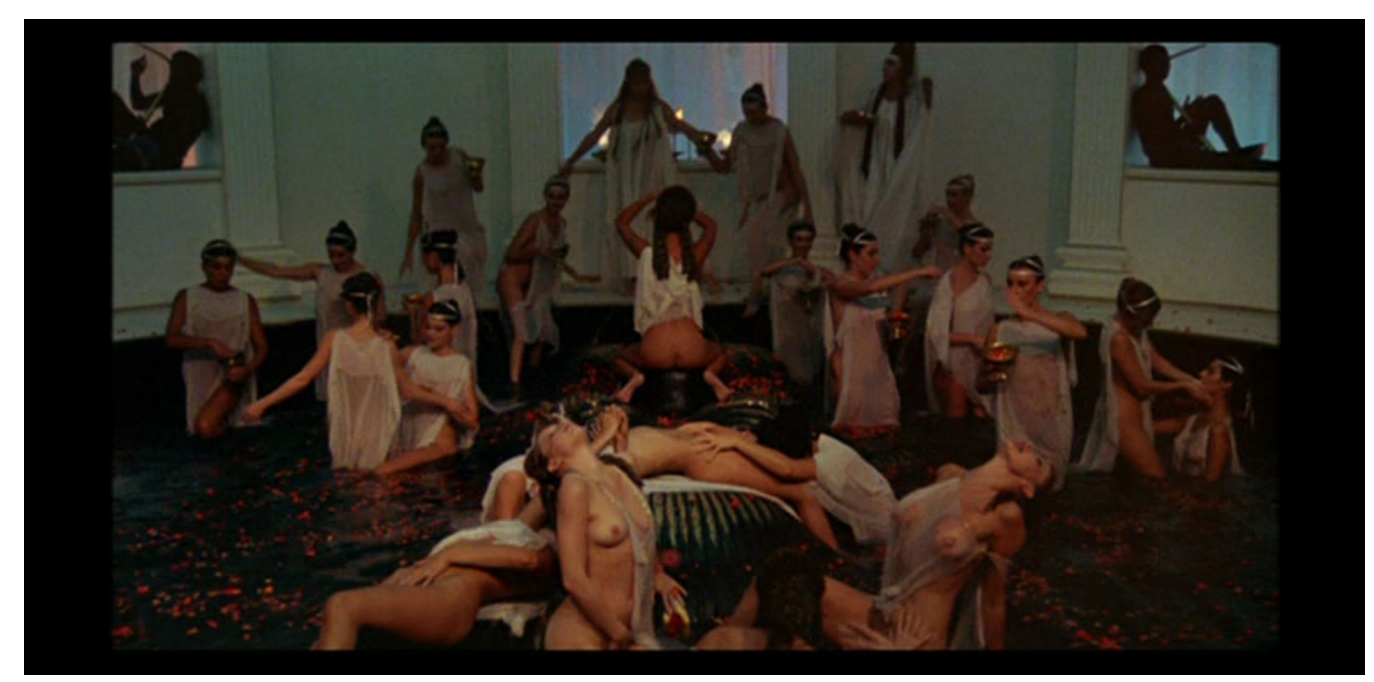

F5. Escena de Calígula en busca de una mujer. Calígula, Tinto Brass, 1979 
La escena vuelve a estar cargada de elementos explícitamente sexuales donde mujeres, dentro de un sobresaliente, en el centro de la piscina, juegan entre ellas en una especie de orgia lésbica. En esta composición del director de arte podemos apreciar a las mujeres en la piscina y el círculo de columnas nos recuerda a composiciones de algunos números de la revista Penthouse.

En el transcurso de la escena, Calígula se percata de dos mujeres que les resultan atractivas, una de ellas es Livia, una virgen que está a punto de casarse con el joven oficial Próculo y una divorciada con experiencia sexual, Caesonia, la cual no es del gusto de Drusilla, pero finalmente Calígula la selecciona como su futura esposa.

\section{Escena 22}

Caesonia es invitada a una habitación anexa al recinto de la escena previa, en ella Calígula en un acto de dominación, le hace una herida y procede a sorber la sangre que brota de ella. Acto seguido, le indica que se tumbe, pero él la acaba poniendo en otra postura para mantener sexo anal con ella en una señal de quién es el César y que ella debe ser sumisa a sus deseos como esclava en el sexo y en el día a día.

Esta escena tiene un alto grado de iconicidad y está repleta de códigos que intentan impregnar al espectador de la sensación de que los personajes están realmente consumando. Para ello, el director, con el juego de planos, encuadres y el punto de vista, simula el hecho.

Es cierto que esta intención no se da ya que los actores deben creer en lo que están haciendo y, en este caso, lleguen a ser seductores. A menudo los espectadores no están seguros de que los actores estén experimentando algo y una escena de sexo erótico que no transmita, se queda en algo sinsentido dentro de la película. Ciertamente, estos actores no demuestran la emoción de un encuentro satisfactorio como es una relación sexual que dispara la adrenalina y genera una situación de éxtasis en aquellos que lo suelen practicar. 


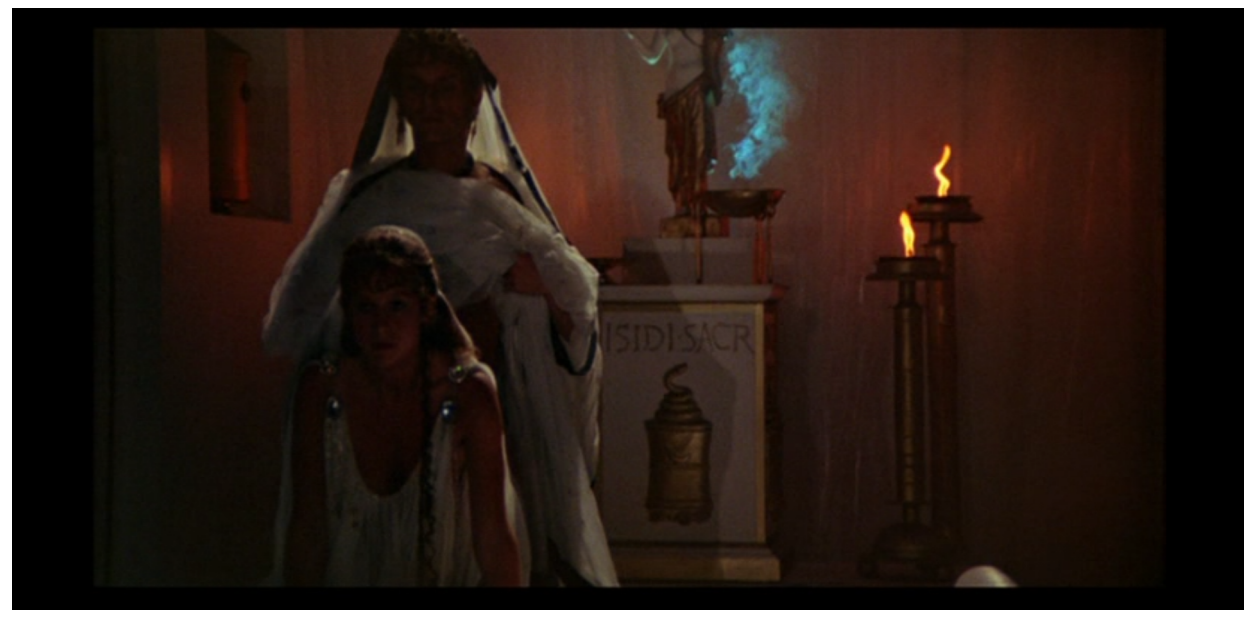

F6. Escena de Calígula consumando con Caesonia. Calígula, Tinto Brass, 1979

\section{Escena 43}

Dada la crisis económica que sufre Roma, Calígula propone un burdel como fuente de ingresos. Esta escena contempla un grado de iconicidad en el desarrollo de la escenografía, representando los navíos que eran de grandes dimensiones, lujosamente equipadas y dotadas de ingenios náuticos muy innovadores para la época.

Esta escena desafía la lógica ya que propone que las mujeres de los senadores sean las prostitutas y así equilibrar el presupuesto del estado con lo que se ingresará de los hombres más ricos de Roma (los ladrones). Esta situación nos recuerda un poco que Calígula se convierte en una especie de Robin Hood, pero en esta situación, se lo quita a los ladrones para dárselo a Roma (aunque no se especifica si es por el bien de la ciudad o por el bien de su imperio personal, lo que nos recordaría a lo que Tiberio hacía con las posesiones de los senadores). Esta forma de presentarnos a este Calígula cercano a su muerte, ya enloquecido por la muerte de Drusila. Es decir, es una clara representación de los niveles de locura a los que llega Calígula.

\section{Conclusiones}

A lo largo de esta investigación, hemos podido apreciar que nos hallamos ante la confusión en la categorización del cine erótico y del cine pornográfico. Ello nos ha supuesto un reto porque la película que nos concierne en esta 
investigación se puede clasificar tanto como erótica como pornográfica dependiendo de la literatura que usemos. Todo esto se debe a que algunos consensuan que categorizar una película como pornográfica debe reducirse al número de veces que salgan genitales dentro del plano, mientras que otros postulan que no debe ser cuestión de números, sino de cómo se plasman y cómo son tratados esos genitales en cuanto al plano, etc.

Es cierto que a veces la desnudez en Calígula es abrumadora y gratuita con esos extras masculinos que actúan como trabajadores o soldados en escenas que no tienen la necesidad de mostrarse desnudos. Lo que hace plantearnos si Calígula tenía la intención de ser realista o por el contrario fantasía. Hay que destacar que la desnudez, por supuesto, no significa necesariamente sexo, algo que podamos apreciar en diferentes escenas.

Así mismo, en el cine pornográfico el sexo tiene poco de natural y espontáneo, se representa solo y exclusivamente para la cámara, para que lo registre con claridad, con todos los condicionantes diegéticos y extradiegéticos que ello conlleva (Mendíbil Blanco et al, 2017, p. 158) y eso es lo que podemos apreciar en las escenas rodadas por Guccione para su versión final y que posteriormente se censurarían para que se pudiera exhibir. Podemos destacar las interesantes palabras de Lipkau Henríquez (2009, p. 233) cuando decía de construir películas que funcionen como declaraciones de amor hacia la humanidad y en favor del entendimiento humano y este tipo de películas es una muestra de un verdadero filme erótico que es capaz de retener la esencia a la que se refiere Lipkau Henríquez.

Así mismo es interesante matizar de la escena 22 cómo ilustra acertadamente la diferencia entre la mayoría de las películas para adultos y las películas tradicionales hasta entonces. Siendo las películas pornográficas las que venden actos sexuales visuales explícitos, donde gracias a una pista de audio apropiada, generalmente con pocas palabras, gruñidos o gemidos se consigue la finalidad de excitar al espectador sin importar la narración de la película por su escaso o nulo guion. 
Esta es una de las pocas escenas que deberían haber ilustrado lo razonable que el sexo explícito forme parte de las películas tradicionales al agregar algunos marcos más de interpretación del amor, ya que técnicamente, los actores reales podrían haber sido sustituidos por otros que llevaran a cabo los actos reales que esta escena reclama por su contenido narratológico y su importancia en la propia historia.

Las escenas propuestas para esta investigación muestran un alto grado de iconicidad, de donde podemos destacar la 6 por como el director plantea un argumento narrativo sobre la tiranía del poder rodeando y envolviendo la escena en un colorido rojo dentro de una cueva oscura, donde los personajes de Tiberio y Calígula van a mantener esta conversación rodeados de actos sexuales, algunos incluso muy explícitos.

En el cómputo de las escenas, Tinto Brass hace un excelente uso de los distintos tipos de planos para ayudar al espectador a introducirse en la historia y vivirla, gozando de aquellas escenas de los cuerpos desnudos de bellas mujeres que tanto le gustaba mostrar en todas sus películas.

Muchos de esos planos invitan al espectador a hacer un barrido por la escena, e incluso con ayuda del zoom guiarle al elemento que el director quiere que se percate el espectador por su relevancia (como ocurre con un cuervo que vuela sobre la cama de Calígula).

El cine erótico, y por ende el pornográfico también, tiene un componente de voyeurismo del que Tinto Brass se ha complacido desvergonzadamente tanto por él mismo como por el espectador que desea ver sus películas. Este voyerismo se manifiesta dentro de sus películas cuando Calígula y Drusilla están en la cama y son espiados por dos hombres que son descubiertos infraganti manteniendo relaciones sexuales. Esta forma de trabajar el cine erótico da un valor a los aspectos visuales como mecanismo que atrapa y engancha al espectador de este género que lo que anhela con su visionado es dar rienda suelta a sus instintos y deseos que no puede llevar a cabo en su vida. Como ejemplo de esto, podemos citar All ladies do it (Cosi fan tutteTinto Brass, 1992) donde se muestra que los labios en la pantalla son reales, 
sin embargo los genitales masculinos erectos que sobresalen constantemente de los pantalones son claramente prótesis de plástico. Esta versión low cost de sexualidad masculina hace preguntarnos sobre la verdadera intención del propio director: ¿quería Tinto Brass burlar así la censura del momento al hacer cómico y ridiculizarlo de forma que no fuera creíble su censura? O por el contrario quiso parodiar los excesos de la pornografía en la que los actores están constantemente preparados para la actividad sexual y nunca sufren una disfunción eréctil. Esta película de los noventa nos llega a mostrar como Tinto Brass quería que el sexo en el cine fuera una forma artística de mostrar la realidad y no destrozarla con un deseo de excitación sexual con fines comerciales o promocionales como pasó con esta película. Por el contrario, Guccione en su intento de introducir esos 18 minutos de sexo explícito no consigue llevar a esta película al género pornográfico, ya que como hemos visto, para que pueda considerarse este género, la cinta perdería sentido narrativo si las escenas sexuales fueran eliminadas. El productor, en este caso, lo que consiguió fue que sus escenas fueran un poco más subidas de tono.

En Calígula, la versión de Tinto Brass nos hace reflexionar y meditar sobre la gran diferencia entre el disfrute contemplativo de un desnudo o de una relación sexual con amplios significados dramáticos, estéticos, humanos y la complacencia mediante la excitación sexual o las puras impresiones sexuales por el estilo en la pornografía (Rojas Bez, 1997, p. 49). La versión de Guccione tiene un fin de complacencia mediante la excitación sexual que claramente está más que sobrevalorada por el productor que ha deteriorado la calidad de la historia y por consiguiente del filme con determinadas escenas que han sido colocadas sin un sentido narratológico para excitar a la audiencia de forma gratuita y banal.

Los valores impactantes del personaje histórico que se conservan en esta versión de Calígula se intensificaron y se resumen en su lanzamiento mundial bastante potente por parte del productor donde, pese a la oposición de muchos críticos, distribuidores y los propios censores del gobierno que trataron de remodelar este filme, el futuro inevitable que marcó a esta 
película es el que conocemos. Pero es que poco se podía hacer. En Calígula, la violencia dominó al sexo hasta tal punto que el sexo se convirtió en violencia así mismo, por lo tanto, se mostraron inseparables dentro del filme (sexo y violencia se conjugan en toda la película de una u otra forma como sucede en la escena 5).

Podemos decir que en esta película vemos un intento de una "película histórica" pero donde no se trabajó los detalles escenográficos al nivel que la producción pedía con el presupuesto con el que se desarrolló, apreciándose en algunos planos incluso la falta de calidad de ellos. Del mismo modo, cabe destacar que la estética primó por encima de la exactitud histórica, y la licencia histórica es más habitual de lo que se espera de una película de esta categoría. Es cierto que, por otro lado, el director de fotografía hizo un gran trabajo con una iluminación artificial, de tono algo fantástico, lo que en casi toda la pieza va jugando con las percepciones del personaje de Calígula, de sus emociones e incluso de su salud mental recordándonos a Satiricón.

Así mismo podemos decir que esta película, se puede catalogar dentro del cine softcore (filmes eróticos con un argumento más consistente y que en muchos casos estaban inspirados en originales literarios de cierto prestigio, rodados sin llegar al sexo explícito pero con un estilo muy cuidado), aunque en este caso el productor lo consideró insuficiente, y una vez rodado, decidió rodar algunas escenas y planos más explícitos que pueden ser considerados como pornografía y que se añadieron a su versión final. Porque como ya hemos dicho anteriormente, el cine pornográfico pierde todo (narratológicamente hablando) si las escenas sexuales se eliminasen, y es que esto no pasa con el filme Calígula.

\section{Referencias bibliográficas}

Aranda López, F. (2015). El cine del destape (II): Erotismo y pornografía desde los inicios del cine hasta la década de 1960. Mito. Revista Cultural. Recuperado de http://revistamito.com/el-cine-del-destape- 
ii-erotismo-y-pornografia-desde-los-inicios-del-cine-hasta-la-decada$\underline{\mathrm{de}-1960}$

Arce, J. (2014): Con "S" de sexo. Representaciones musicales en el cine erótico de la transición. Quaderns. 9.

Ares, L. y Pedraz Poza, S. A. (2011): Sexo, poder y cine. Relaciones de poder y representaciones sexuales en los nuevos relatos pornográficos. ICONO 14, Año 9, Esp., 98-119

Arroyo Martínez, L. (2010). El erotismo literario en las adaptaciones cinematográficas: Estudio de siete ejemplos. Cauce. Revista internacional de Fỉlología, Comunicación y sus Didácticas. 32

Bordwell, D. (1995). El significado del filme. Barcelona: Paidós.

Calleja, P. (2013). Cine caliente. Teià, Barcelona: Ma Non Troppo.

Carmona, L. (2010). Cine erótico a la europea. Madrid: T \& B.

Casetti, F., y Di Chio, F. (1994). Cómo analizar un film. Barcelona: Paidós.

Forshaw, B. (2015). Sex and Film. The Erotic in British, American and World Cinema. Nueva York: Palgrave Macmillan (Edición Ebook)

García Gómez, F. (2017). Sexo y erotismo en el cine: lo que ha llovido desde El beso. Fotocinema. Revista científica de cine y fotografía, 15, 5-11.

Gómez Tarín, F. (2006). El análisis del texto fílmico. Portugal: Universidade da Beira Interio.

González Caldito, J. (2015). Cadenas, poder y pornografía. Mito. Revista Cultural. Recuperado de http://revistamito.com/cadenas-poder-ypornografia

Gubern, R. (2005). La imagen pornográfica y otras perversiones ópticas. Barcelona: Anagrama.

Lipkau Henríquez, E. (2009). La mirada erótica. Cuerpo y performance en la antropología visual. ANTÍPODA. 9, 231-262

Malpartida Tirado, R. (2012). El erotismo, de la novela al cine: el caso de Bigas Luna. Analecta Malacitana. Electrónica 32.

Mendíbil Blanco, A., García García, F. y García Guardia, M. L. (2017). Narratología porno. Una lectura semiótica de Tras la puerta verde. Fotocinema. Revista científica de cine y fotografía. 15, pp. 155-177. Disponible http://www.revistas.uma.es/index.php/fotocinema/article/view/3504 L3215. doi:http://dx.doi.org/10.24310/Fotocinema.2017.voi15.3504.

Reidar, D. (2013). Love in Motion. Nueva York: Wallflower Press.

Rodrigues, N. S. (2014). A Antiguidade no cinema: Caligula de Tinto Brass e Bob Guccione (1979). Boletim de Estudos Clássicos, 59, 137-152,

Rodriguez Centeno, J.C. y Corredor, J. (1997). Publicidad y cine erótico en la prensa de la transición. Questiones Publicitaria. 6 
Rojas Bez, J. (1997). Erotismo, pornografía y cine. Chasqui. Revista Latinoamericana de Comunicación. 57, 47-50

Rouner, J. (2014). What It's Really Like To Write Porn For A Living. Your Tango. Recuperado https://www.yourtango.com/2014224426/what-its-really-like-towrite-porn-for-a-living

Schaefer, E. (1999). Bold! Daring! Shocking! True! A History of Exploitation Films, 1919-1959. Durham: Duke University Press. 